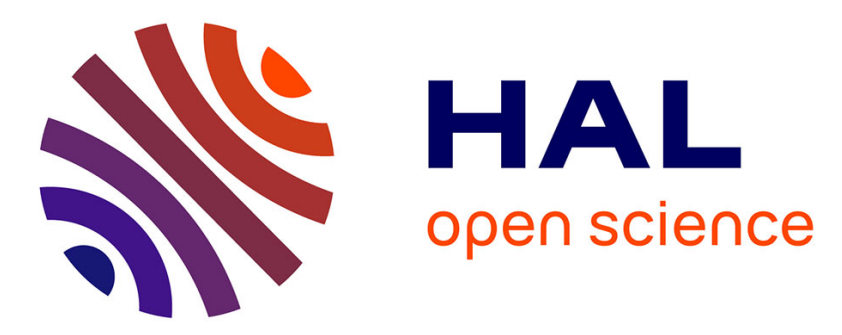

\title{
Extraction of Indium From Sulphate Solutions with D2EHPA Solutions Using Static Mixers
}

\author{
N. Nacevski, F. Poposka, B. Nikov
}

\section{To cite this version:}

N. Nacevski, F. Poposka, B. Nikov. Extraction of Indium From Sulphate Solutions with D2EHPA Solutions Using Static Mixers. Journal de Physique IV Proceedings, 1995, 05 (C7), pp.C7-135-C7-142. 10.1051/jp4:1995712 . jpa-00254005

\section{HAL Id: jpa-00254005 https://hal.science/jpa-00254005}

Submitted on 1 Jan 1995

HAL is a multi-disciplinary open access archive for the deposit and dissemination of scientific research documents, whether they are published or not. The documents may come from teaching and research institutions in France or abroad, or from public or private research centers.
L'archive ouverte pluridisciplinaire HAL, est destinée au dépôt et à la diffusion de documents scientifiques de niveau recherche, publiés ou non, émanant des établissements d'enseignement et de recherche français ou étrangers, des laboratoires publics ou privés. 


\title{
Extraction of Indium From Sulphate Solutions with D2EHPA Solutions Using Static Mixers
}

\author{
N. Nacevski, F. Poposka and B. Nikov \\ Faculty of Technology and Metallurgy, "St. Cyril and Methodius" University, 91000 Skopje, Republic \\ of Macedonia
}

\begin{abstract}
The possible use of static mixers as a reactor for the extraction of indium from sulphate solutions was investigated. The experimental work was focused on "Kenics" type static mixers, since these were found simplest and cheapest among a variety of models, and yet yielded acceptable preliminary results with low pressure drop along the reactor.

A series of experiments was carried out in a stirred continuous flow reactor to compare the results. It was found that under certain (different) conditions both reactors perform satisfactorily. The energy consumption of a static mixer is of the same order of magnitude as that of a stirred vessel. The most significant achievement of the experimental work is establishing that the residence time in a static mixer is about two orders of magnitude less than that in a stirred reactor.
\end{abstract}

\section{Introduction}

There is considerable and permanently increasing interest in applying solvent extraction to the recovery of speciality metals found in the residues arising from the hydrometallurgy of zinc [1]. Principal amongst them are gallium, indium and germanium, which can be recovered by leaching the iron precipitation residues or the metallic cements formed during the purification of zinc electrolytes [2]. However, the residues arising from some pyrometallurgical processes for lead, zinc and copper are also attractive, particularly for indium recovery $[3,4,5]$.

Modern hydrometallurgical processes more frequently include solvent extraction for concentration and purification of the solutions. Industrial setups for rare metal extraction are usually based on conventional mixers in which the stirrer has the role of creating a large surface area and turbulence, both having a positive effect on the mass transfer rate, and settlers in which the two liquid phases are separated by gravity. The principal disadvantage of a mixer-settler system is the wide range of drop diameters of the suspended liquid. The rotational speed of the impeller must be large in order to create a large interfacial area and thereby to enhance the overall mass transfer rate. As a result the separation of the two phases becomes slow due to the formation of very small drops near the impeller blades and larger settlers are required [6].

The use of static mixers instead of mixer-settlers provides an interesting alternative. They consist of elements arranged inside a tube in such a way that they promote radial mixing. Thus they exhibit approximately the plug flow characteristics of two concurrently flowing liquids.

\section{Experimental}

\section{Apparatus}

Kenics type static mixers consisting of 24 polypropylene elements were purchased from Cole and Parmer Instruments Co. Each element is a $180^{\circ}$ section of a left or right-handed helix. The elements are alternated and placed with their leading and trailing edges at $90^{\circ}$ angles. The elements of the particular mixer used in the experiments were $6 \mathrm{~mm}$ long and $6 \mathrm{~mm}$ in diameter. The central part of the reactor (Fig. 1) is a $150 \mathrm{~mm}$ long, $6 \mathrm{~mm} \mathrm{ID}$ glass tube in which the static mixer is placed. Sampling openings are provided every $30 \mathrm{~mm}$ from the point where the two liquids come into contact.

The organic phase is fed through the inner $4 \mathrm{~mm}$ ID tube of the feeding system by means of a Masterflex peristaltic pump. Depending on the selected O/A phase ratio, the aqueous phase is fed through the outer tube by means of one or more pumps set on the same drive. 
The sampling openings are used for measuring the pressure drop along the static mixer reactor.

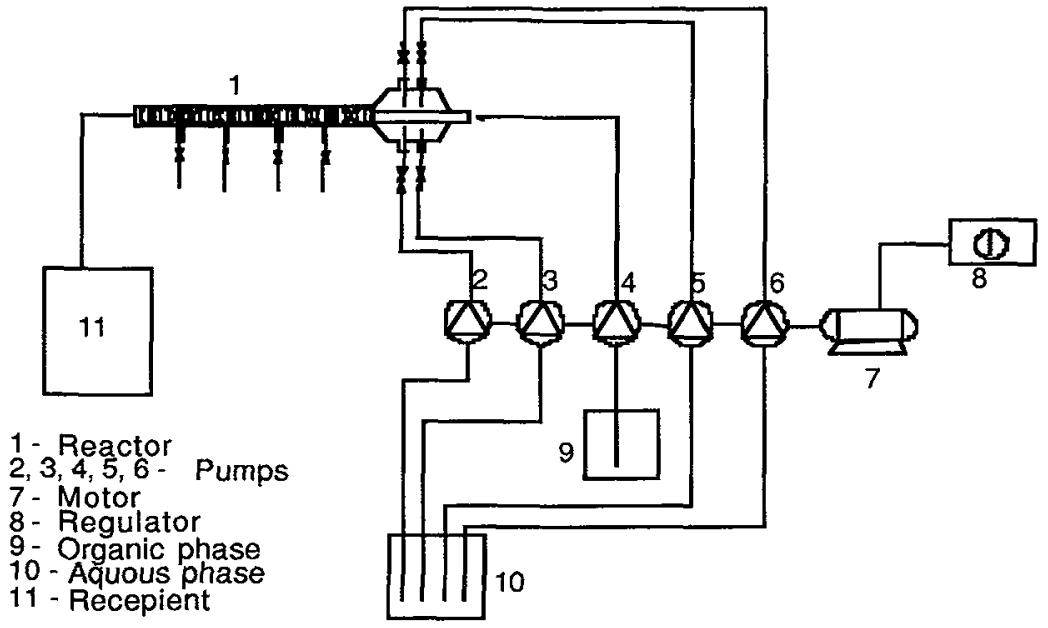

Figure 1 : Flowsheet of experimental apparatus

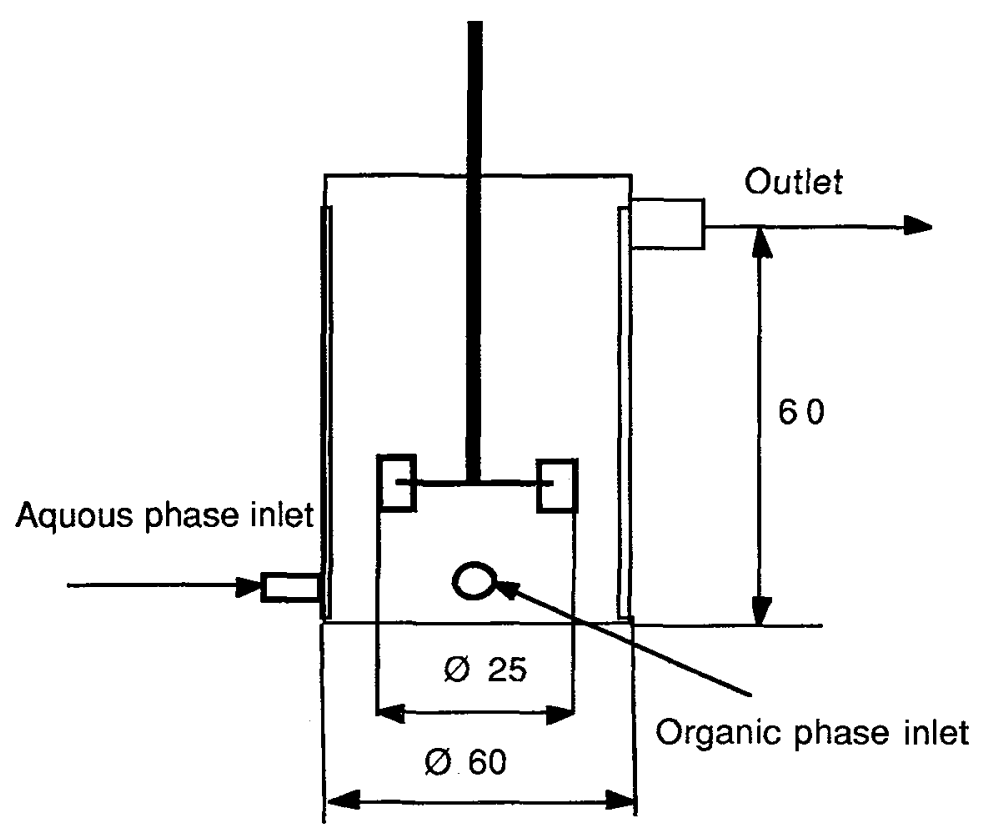

Figure 2 Impeller stirred reactor

The stirred tank reactor (Fig. 2) is made of fibre-glass. A turbine type impeller was used, the rotation speed was measured by means of a stroboscope probe and controlled by a rheostat. 


\section{Materials and procedure}

Although certain quantities of $99.99 \%$ indium have already been produced at the "Zletovo" smelter, a metallic sample of the same purity received from MHO (Belgium) was used for preparing aqueous solutions. DEHPA was purchased from Merck and used without prior purification despite the presence of monoester. Kerosene produced at the oil refinery in Skopje was used as diluent. Most of the experiments were carried out with $1.74 \cdot 10^{-2} \mathrm{~mole} / \mathrm{dm}^{3} \mathrm{In}$ in the aqueous phase and $0.3 \mathrm{~mole} / \mathrm{dm}^{3} \mathrm{DEHPA}$ in kerosene as the organic one.

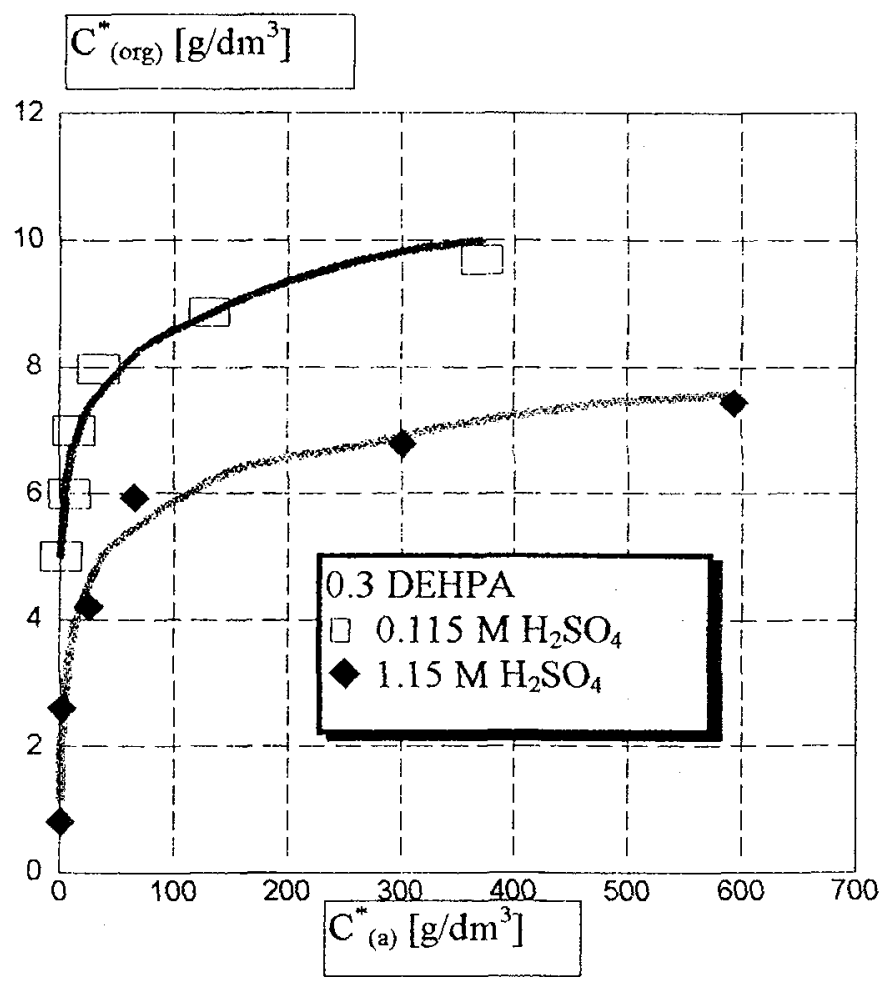

Figure 3 Extraction isotherms for indium

Equilibrium parameters of the $\mathrm{In}^{3+}-\mathrm{H}_{2} \mathrm{SO}_{4}-$ DEHPA were studied earlier. Fig. 3 shows extraction isotherms of indium for two different concentrations of $\mathrm{H}_{2} \mathrm{SO}_{4}$. Both the organic and the aqueous phases are pumped into the static mixer reactor by means of peristaltic pumps at predetermined rates and ratios. A few seconds afterwards a steady state condition is established and samples are taken through the sampling valves in small separating funnels. In order to minimize the effect of additional mass transfer, only the first few millilitres of the aquevus phase from the funnel are poured into a sampling tube. The concentration of indium in the aqueous phase was determined on an ARL ICP-plasma spectrophotometer. 


\section{Results and discussion}

Fig. 4 indicates that extraction efficiency increases with flowrate within the entire range from 0 to $7 \mathrm{~cm}^{3} / \mathrm{s}$. This means that the enhancement of mass transfer rate and interfacial area by increasing the flowrate is very sharp and overcomes the negative effect of the decrease in residence time. In the case of a fixed flowrate, the extraction efficiency increases along the reactor as its length is a linear function of time (Fig. 5).

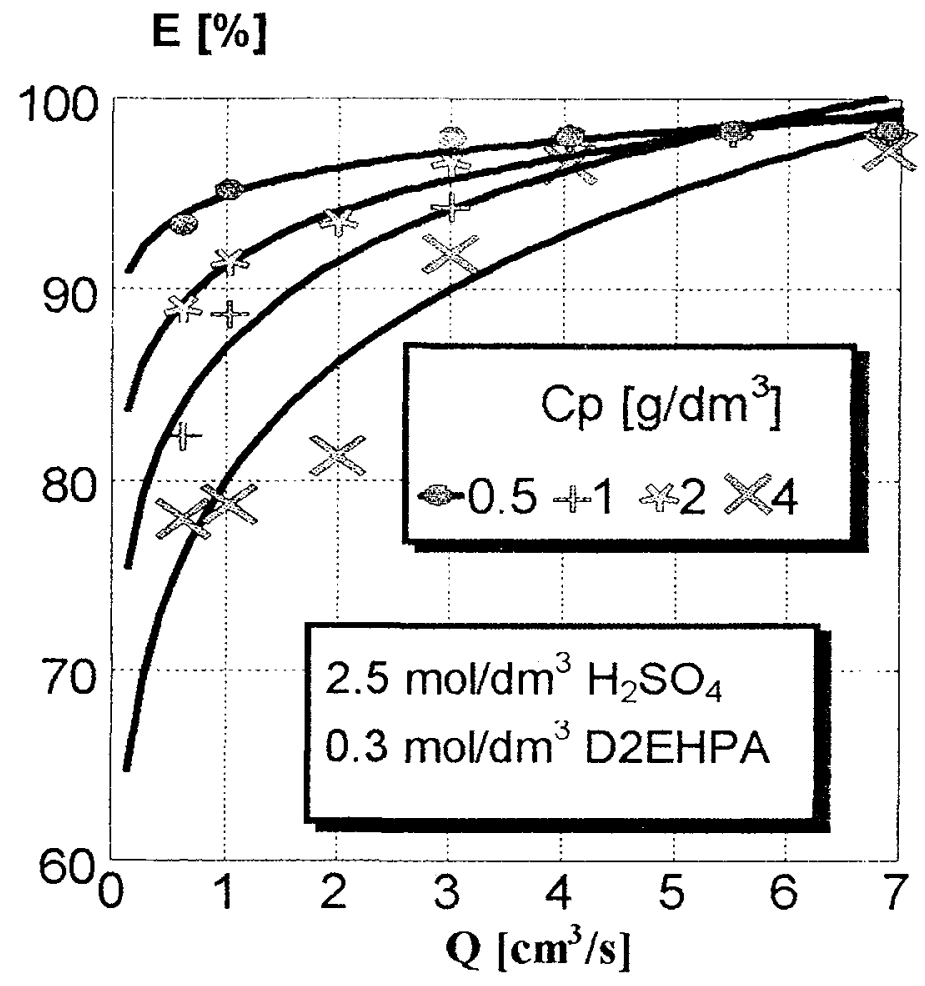

Figure 4 Percent efficiency as a function of flowrate for various initial concentrations of In in aqueous phase

The concentration of DEHPA in kerosene makes a great impact on the extraction efficiency. As the O:A ratio was maintained constant and equal to one during the experiments with different initial concentrations of DEHPA, obviously, different loadings of the organic phase were obtained, depending on the initial concentration of indium in the aqueous phase. Park and Neuman [7] report that a conventional slope analysis based on the equilibrium distribution of the metal is not reliable in such conditions, since the stoichiometric coefficients of the chemical reaction change in a very complicated manner as the loading coefficient of the solvent increases. Our experimental results are in accordance with the above, and therefore It was practically impossible to evaluate a reliable mathematical expression. Nevertheless, a decrease in the extraction efficiency with a decrease in the initial concentration of DEHPA in kerosene is evident, especially in case of higher initial concentrations of indium in the aqueous phase (Fig. 5). 

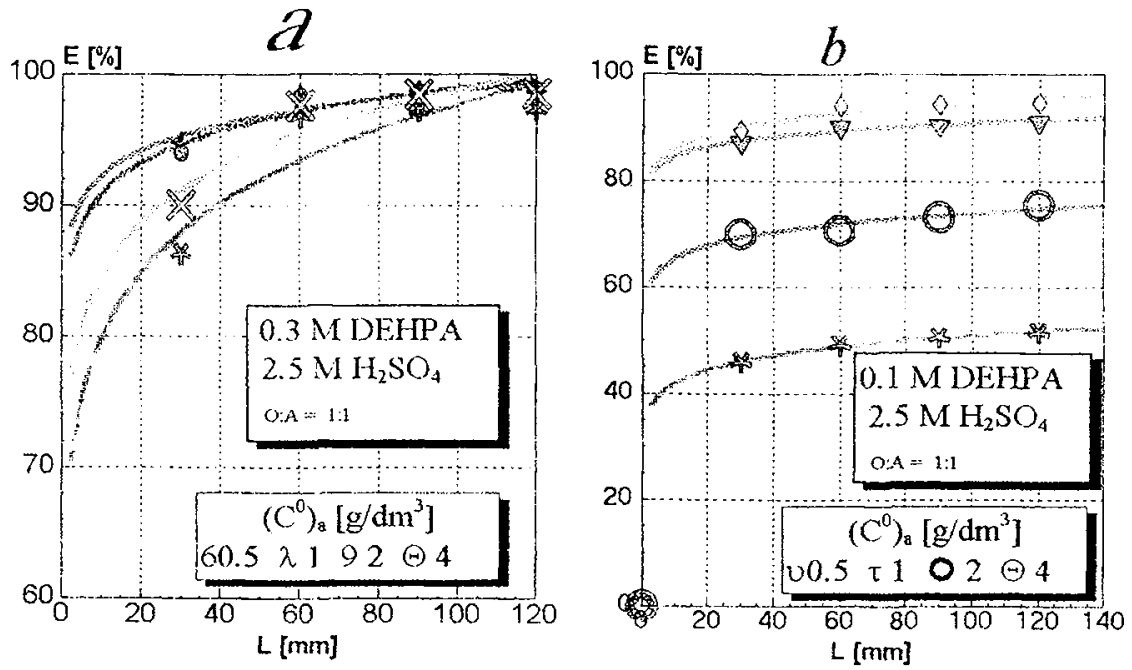

Figure 5 Plot of extraction efficiencies Vs length of the reactor a: 0.3 M DEHPA, b:0.1 M DEHPA

Extraction efficiency depends very much on the ratio of organic to aqueous phase. The change in the phase ratio can be performed by either maintaining a constant total throughput of the reactor (Fig. 6) or the flowrate of one of the phases (Fig. 7). In the first case an increased ratio of the aqueous phase leads to higher loading of the organic one : consequently, decreased extraction efficiency is obtained. If the phase ratio is changed by maintaining a constant flowrate of one of the phases, the hydrodynamic conditions of the system will change noticeably, further reducing extraction efficiency.

Since mixing in a static mixer is performed by obstructing the flow, an appreciable pressure drop arises along the reactor. The pressure drop increases with the flowrate (Fig. 8), but a higher O:A ratio acts in the same direction (Fig. 9). Compared to the water-kerosene system, addition of any other component $\left(\mathrm{H}_{2} \mathrm{SO}_{4}\right.$, $\mathrm{In}^{3+}$, DEHPA) increases the pressure drop along the reactor. Such dependence coincides with the change of the interfacial tension of the system.

The impeller stirred reactor requires a longer residence time for the same extraction efficiency compared to the static mixer reactor. A high rotational speed of the impeller is essential if the necessary contact surface is to be provided. Nevertheless, it has been found that, under certain conditions, acceptable results can be achieved in a stirred reactor as well (Fig. 10). So the eventual decision of the type of the reactor will depend on the process and economical parameters such as power consumption, operational costs etc. 


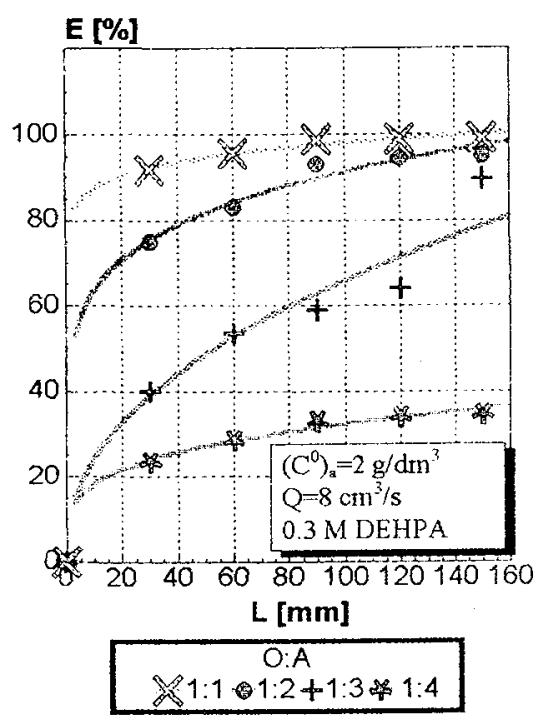

Figure 6 Effect of phase ratio on extraction efficiency in the case of a constant total flowrate

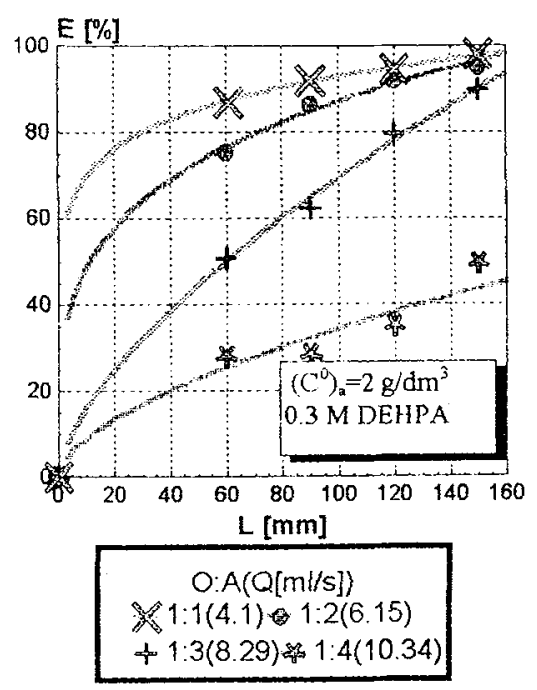

Figure 7 Effect of phase ratio on extraction efficiency in the case of a constant flowrate of the organic phase

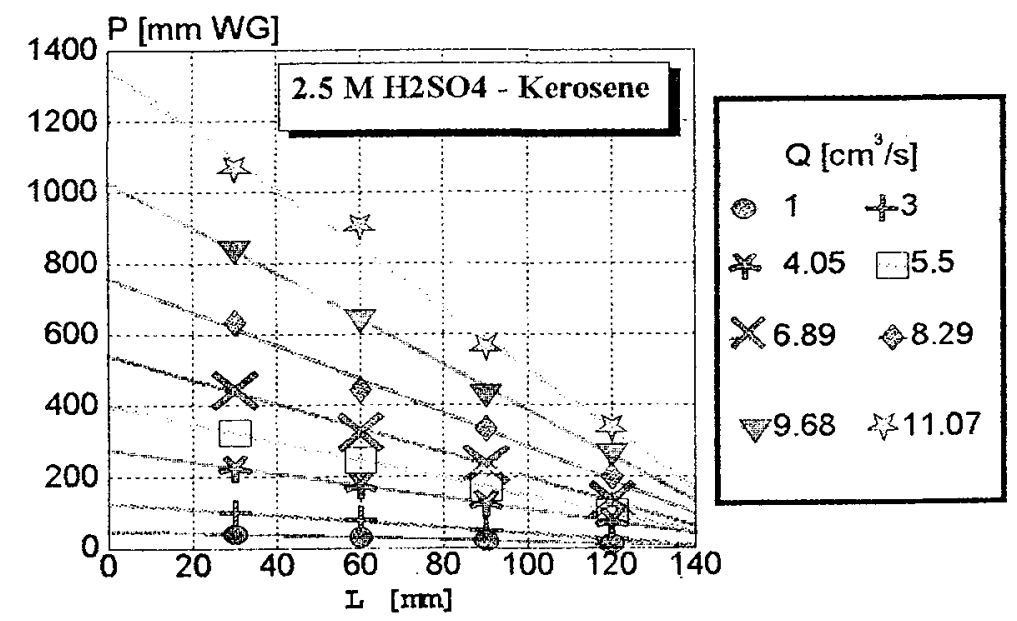

Figure 8 Effect of flowrate on the pressure drop along the static mixer reactor for the H2SO4-Kerosene system 


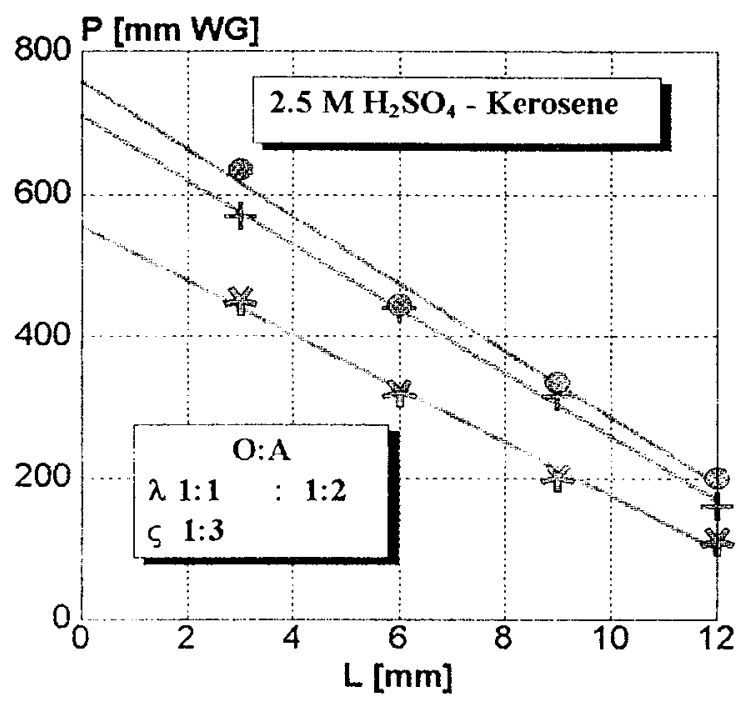

Figure 9 Effect of organic phase ratio on pressure drop

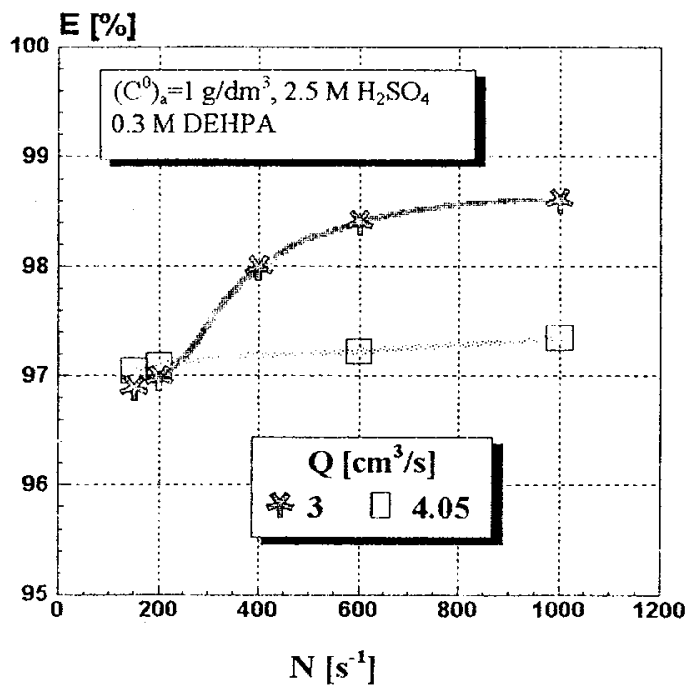

Figure 10 Effect of impeller speed and flowrate on extraction efficiency in a stirred reactor 
The residence time for a total flowrate of $8.3 \mathrm{~cm}^{3} / \mathrm{s}$ through a $150 \mathrm{~mm}$ long, $6 \mathrm{~mm}$ ID reactor with a $1 \mathrm{~mm}$ thick Kenics type motionless mixer inside, is

$$
\tau_{1}=\frac{\frac{\pi D^{2} L}{4}-\delta D L}{Q}=\frac{\frac{\pi \cdot(0.6)^{2} \cdot 15}{4}-0.1 \cdot 0.6 \cdot 15}{8.29}=0.403 \mathrm{~s}
$$

where

$$
\begin{aligned}
& \tau_{1} \text { - mean residence time in the static mixer } \\
& D \text { - inside diameter of the reactor } \\
& L \text { - reactor length } \\
& Q \text { - total flowrate } \\
& \delta \text { - thickness of the mixer plate }
\end{aligned}
$$

The stirred reactor shown in Fig. 2 has a volume of $165 \mathrm{~cm}^{3}$. A flowrate of $3 \mathrm{~cm}^{3} / \mathrm{s}$ corresponds to a residence time of $55 \mathrm{~s}$ which is more than 100 times longer than that in the static mixer.

Power consumption in the static mixer can be calculated from the flowrate of the fluid and the corresponding pressure drop. According to figs. 8 and 9 , a flowrate of $8.3 \mathrm{~cm}^{3} / \mathrm{s}$ builds a pressure drop of $740 \mathrm{~mm}$ WG. Therefore:

$$
N_{1}=\Delta P \cdot Q=740 \cdot 8.29 \cdot 10^{-6}=6.13 \cdot 10^{-3} \mathrm{kgm} / \mathrm{s}
$$

In the case of the stirred vessel the power number was determined according to the diagram [8], and power consumption was calculated from the equation

$$
\Phi=\frac{N_{2}}{n^{3} d^{5} \rho}
$$

in which

$\mathrm{N}_{2}$ - power consumption in the agitated vessel

$\mathrm{n}$ - agitation speed, rps

d - turbine diameter

$\rho$ - mean density of the fluid

For $\operatorname{Re}=1.08 \cdot 10^{4}, \mathrm{~F}=0.225$ and $\mathrm{N}_{2}=8.75 \cdot 10^{-3} \mathrm{kgm} / \mathrm{s}$

According to the results obtained so far, there is no significant difference in power consumption between these two reactors. The static mixer reactor might have some advantage over the stirred reactor due to the very short residence time, i.e. the very small reactor volume. Each individual application requires detailed analysis for the selection of equipment, but there will always be room for the designer's preference.

\section{References}

1. Monhemius J. A., 1994, Bull. Chem. Technol. Macedonia, 13, 2 (in print).

2. Demarthe J.M., Rousseau A.M. and Fernandez F.L., 1990, in Lead-Zinc '90, T.S. Mackey and R.D. Prengaman (Eds.), TMS, 151-160.

3. Nikov B., Stojanov P., Stojadinovic T., 1994, Hydrometallurgy '94. 1153-1164, Chapman \& Hall, London.

4. Masatosi T. et als., 1983, in PЖM .5Г, .51319, 45

5. Мальдев Г. И. в др., 1985, ЦҺветиая мсталлуріия, 5, 101-106.

6. Merchuk J. C., Shal R., Wolf D., 1980, Ind. Eng. Chem. Process Des.

7. Park S. J., Neuman R. D., 1992, Process Metallurgy 7A, Elsevier Sci. Publish., 201-206.

8. Хемпско Техволошки Приручннк, књнка пета, 1987, str. 225, "Rad" Beograd. 